\section{Editorial - Integrating Industrial Metrology: Application to Biotechnology}

Ravindra NM

Department of Physics, New Jersey Institute of Technology, Newark, NJ, USA

\section{Editor Note}

As an interdisciplinary science, engineering and technology, Metrology deals with all the theoretical and practical aspects of measurements, at any level of uncertainty. The demands on measurement accuracy as well as the utilization of in-situ/ex-situ methods and contact/non-contact sensors continue to be on the rise.

Industrial Metrology is also termed as Applied or Technical Metrology as it applies the innovations of the measurement science to methods in manufacturing and other sectors for ensuring the application and implementation of measurements in the instruments that are required for calibration, process repeatability and reproducibility, quality control and manufacturing yield.

The Journal of Scientific and Industrial Metrology is an open access peer reviewed international journal that publishes scientific articles related to all the aspects of Acoustics, Astronomy, Electricity and Magnetism, Fundamental Units of Length, Mass and Time, Fluid Flow, Materials, Optics, Particle Physics, Thermometry, Ultrasound, etc. The current Volume No. 1 , Issue 2 of the journal presents three research papers and a review article.

Zhou et al. describe a systematic way for characterization and measurement of absorbing materials which is on par with the NRL arch reflectivity test [1]. Papp et al. propose a method for measuring radiation without the inversion problem. The
Corresponding author: Nuggehalli M Ravindra

§nmravindra@gmail.com

Department of Physics, New Jersey Institute of Technology, Newark, NJ, USA.

Tel: +973.596 .3278$

Citation: Ravindra NM. Editorial - Integrating Industrial Metrology: Application to Biotechnology. J Sci Ind Metrol. 2016, 1:2.

authors have applied two new methods for Gamma Spectra measurements for 152Eu calibration and have successfully compared their results with measurements obtained by using previous techniques [2].

Hu et al. report a theoretical basis for the calibration of PM2.5 monitors using Aerosol Generator by PGSS Method [3]. Baptista et al., in their review article, discuss the application of metrological rules for biomaterials, tissue maturation etc. [4]. The authors have introduced theoretical concepts for interrelating Biometrology with new approaches in Tissue Engineering. 


\section{References}

1 Zhou T, Wel D, Yang S, Xu G, Ji Ch, et al. (2016) Measurement and Characterization of Flexible Absorbing Materials for Applications in Wireless Communication. J Sci Ind Metrol 1: 6.

2 Papp T, Maxwell JA, Raics P, Balkay L, Gál J (2016) Radiation Measurements without Posing the Inversion Problem. J Sci Ind Metrol 1: 11.
3 Hu D, Zhang Z, Guo B, Li B, Bi H (2016) The Development of PM2.5 Standard Aerosol Generator Based on PGSS Method. J Sci Ind Metrol 1: 6 .

4 Baptista LS, Silva KR, Beatrici A, Fontes GN, Granjeiro JM, et al. (2016) Biometrology in Tissue Engineering: Thoughts and Concepts. J Sci Ind Metrol 1: 6. 